\title{
Cultura Digital e Educação: desafios contemporâneos para a aprendizagem escolar em tempos de dispositivos móveis
}

\author{
Rafaela da Silva Melo${ }^{1}$, Cíntia Inês Boll ${ }^{1}$ \\ ${ }^{1}$ Faculdade de Educação - Universidade Federal do Rio Grande do Sul (UFRGS) - \\ Porto Alegre - RS - Brasil. \\ \{rafaela.melo,cintia.boll\}@ufrgs.br
}

\begin{abstract}
This article aims to present the possibilities that factory Apps platform provides for a mobile learning focused on contemporary challenges of Digital Culture and the development of school learning. It discusses the definitions and the potential benefits of which can also be understood in this context as the contemporary mobile learning. We present three versions of educational applications developed on the platform considering the integration of these digital media and its possible curricular intersections. Justify the importance of this work with the current growth of mobile media applications being developed especially for children and young people who do not have the focus or school education and beyond by creating applications also understand how necessary the creation of educational online repositories for mapping, organization, categorization and availability of these applications.
\end{abstract}

Resumo. Este artigo tem como objetivo apresentar as possibilidades que a plataforma Fábrica de Aplicativos oferece para uma aprendizagem móvel focada nos desafios contemporâneos da Cultura Digital e no desenvolvimento das aprendizagens escolares. Discutimos as definições e os potenciais benefícios do que pode ser também entendido nesse contexto contemporâneo como aprendizagem móvel. Apresentamos três versões de aplicativos educacionais desenvolvidos na plataforma considerando a integração entre essas mídias digitais e suas intersecções curriculares possíveis. Justificamos a importância deste trabalho com o atual incremento de aplicativos para mídias móveis sendo desenvolvidos especialmente para crianças e jovens que não têm por foco nem a educação escolar e além da criação de aplicativos também por entendermos como necessária a criação de repositórios educacionais on-line para o mapeamento, organização, categorização e disponibilização destes aplicativos.

\section{Introdução}

A ampliação do acesso aos dispositivos móveis, consequência de alguns fatores tais como a convergência das telecomunicações e da informática, possibilitaram uma relação estreita entre sociedade e cultura. A sinergia dessa relação ainda na década de 60 fez convergir outras formas de sociabilidades na esfera da comunicação e da mídia promovendo mudanças não só no modo de produção mas também no modo de 
compartilhamento do conhecimento. Uma dessas mudanças é a própria ideia de aprendizagem móvel (Mobile Learning ou m-Learning) que pressupõe novos usos e combinações criativas para dispositivos como Tablets, E-readers e Smartphones (celulares inteligentes $^{1}$ ), outros equipados com áudio, vídeo, SMS e uma variedade de recursos que possibilita a integração das mídias, o compartilhamento de ideias e de experiências culturais.

No Brasil, alguns programas governamentais como o Programa Nacional de Tecnologia Educacional - Prolnfo Integrado (criadores do projeto UCA e Tablet Educacional para professores do Ensino Médio) têm buscado promover o uso didáticopedagógico das Tecnologias da Informação e Comunicação (TIC) na aprendizagem escolar, que articulado à distribuição dos equipamentos tecnológicos nas escolas, alia a oferta de conteúdos às variadas multimídias. Com a Cultura Digital chegando às escolas brasileiras através destes programas governamentais, pesquisas, estudos e discussões sobre novas possibilidades educativas ampliam os espaços de convergências midiáticas para esse fim pois que a base propulsora da aprendizagem escolar se apresenta agora em toda uma comunidade. Uma comunidade que cria redes de comunicação entre a sala de aula e todo o território digital disponível para o acesso. Como exemplo podemos citar os projetos CulturaEduca ${ }^{2}$ e CircuitosdeAprendizagem ${ }^{3}$ onde o necessário entrelaçamento entre a Cultura Digital e os processos educativos estão sendo desenvolvidos por políticas interministeriais entre Ministério da Educação e Ministério da Cultura através dos Programas Mais Educação e Mais Cultura nas Escolas (Boll, 2013, p.97).

Portanto, apresentamos este artigo com o objetivo de sugerir possibilidades de aprendizagem escolar em tempos de dispositivos móveis tendo a plataforma web Fábrica de Aplicativos como foco. Discutiremos as definições e os potenciais benefícios do que pode ser também entendido nesse contexto contemporâneo como aprendizagem móvel e apresentaremos três versões de aplicativos educacionais desenvolvidos na plataforma considerando a integração entre essas mídias digitais e suas intersecções curriculares possíveis.

\section{Aprendizagem Móvel (m-Learning): Novos cenários e possibilidades para ensinar e aprender}

Muitos estudos têm destacado as possibilidades e benefícios na utilização das tecnologias móveis (Smartphones, Celulares, E-readers, Tablets e outros) para acesso aos conteúdos educacionais em qualquer lugar e horário (Tarouco, 2004; Traxter, 2007; Moura; 2006; Valentim; 2009). Tais autores definem a aprendizagem móvel (Mobile Learning ou m-Learning) como a aprendizagem ampliada e apoiada a partir do uso dos dispositivos móveis, tendo como principais características a portabilidade destes dispositivos, sua integração com as diferentes mídias, a mobilidade e flexibilidade dos sujeitos que podem estar tanto fisicamente e geograficamente distantes uns dos outros quanto em espaços físicos formais de aprendizagem escolar.

\section{De acordo com as Diretrizes para as Políticas de Aprendizagem Móvel}

1 Smartphone é um telefone celular com funcionalidades avançadas que podem ser estendidas por meio de programas executados por seu sistema operacional.

2 Disponível em <http://culturaeduca.cc/> Acessado em maio de 2014.

3 Disponível em <http://www.circuitosmaiseducacao.net/> Acessado em maio de 2014. 
(UNESCO, 2013) o uso de tecnologias móveis possibilita a aprendizagem em qualquer momento, em qualquer lugar e por qualquer pessoa, pois as tecnologias móveis atualmente podem estar presentes até mesmo em áreas onde escolas, livros e computadores são escassos. Segundo dados do IBGE (2011), o percentual de pessoas no Brasil com telefone móvel na faixa etária de 10 a 14 anos passou de cerca de $19 \%$ em 2005 para 41\% em 20114, ou seja, a quantidade de crianças com telefone móvel mais que dobrou em um intervalo de 6 anos. Isso significa que cada vez mais pessoas, inclusive aquelas que residem em áreas extremamente pobres, podem ter acesso aos usos e possibilidades educativas se estas forem oferecidas pelas tecnologias móveis no país.

Discussões atuais, considerando os crescentes índices de crianças e jovens com acesso às mídias móveis são não só necessárias mas a cada dia mais desafiadoras para toda a comunidade educadora no país. A perspectiva de uma "sociedade em rede" (Castells, 2002) em que as relações sociais, econômicas e culturais impulsionam e são impulsionadas pelas novas tecnologias transcendendo tempos e espaços também educativos apresenta infinitos desafios ao currículo escolar contemporâneo.

A dimensão da mobilidade comunicacional transcendendo tempos e espaços desloca não só objetos e corpos como também pensamentos e fluxos comunicativos em rede (Lemos, 2009) já que o acesso ao conhecimento está não somente em livros, bibliotecas e "saberes dos mestres" pré-indicados em Projetos Políticos Pedagógicos (PPP) das escolas. Agora o acesso ao conhecimento pode estar tanto próximo ao espaço físico-geográfico quanto próximo ao espaço conectivo de uma rede comunicativa e dilatada que só a mobilidade da Cultura Digital pode oferecer. Uma rede de mídias e culturas no plural convergindo não só em textos midiáticos (sons, imagens e escrita) mas também por meio de ideias e ideais de vida pois que concebemos a internet, tal como Lemos (2003) como um ambiente, "uma incubadora de instrumentos de comunicação e não uma mídia de massa, no sentido corrente do termo" (p. 15).

Assim, entendemos o conceito aprendizagem móvel como a ampliação das possibilidades do processo comunicativo entre alunos que a cada dia mais se tornam conectivos, ampliando territorialidades e vozes nesse outro lugar potencializador de acesso e ressonâncias comunicativas originais. O acesso às tecnologias digitais podem possibilitar aquilo que autores como Lankshear e Knobel (2007) denominam como um novo ethos, enfatizando a descentralização do conhecimento, a diversidade e a promoção da colaboração entre os sujeitos produtores de cultura e da transformação social.

Reconhecendo as possibilidades que as mídias móveis podem oferecer para a potencialidade das aprendizagens escolares em tempos de Cultura Digital, apresentamos os aplicativos desenvolvidos no intuito de informar e fomentar a criação por outros professores e alunos. Numa linguagem acessível procuramos instigar a comunidade educativa que, apesar de possivelmente não possuir conhecimento das linguagens computacionais, poderá desenvolver com o uso desses dispositivos propostas de autoria e de construção do conhecimento colaborativo na sala de aula, em especial nas salas de

4 Disponível em

<http://ftp.ibge.gov.br/Acesso_a_internet_e_posse_celular/2011/PNAD_Inter_2011.pdf> Acessado em abril de 2014. 
aula da educação básica.

\section{A Fábrica de Aplicativos}

Fábrica de Aplicativos ${ }^{5}$ é uma plataforma web brasileira que permite a qualquer pessoa criar e compartilhar aplicativos para celular de forma rápida, intuitiva e sem necessidade de domínio de linguagem de programação. A plataforma foi criada em 2012 por desenvolvedores brasileiros com o objetivo de universalizar o acesso a uma nova economia móvel, digital e criativa, além de empoderar milhões de Appers (como são chamados os criadores de aplicações para dispositivos móveis na cultura digital).

A Fábrica de Aplicativos disponibiliza atualmente três tipos de serviços para criação dos aplicativos: o gratuito, em que desenvolver o aplicativo apenas levará a logomarca da empresa no rodapé; o Sem Banner, em que desenvolver o aplicativo demandará um custo mensal; e, por fim, o Plano Pro, em que desenvolver o aplicativo implica aceitar que os Appers disponibilize seus projetos à venda nas lojas das empresas Google e Apple. Assim, utilizar a plataforma pode envolver tanto projetos educativos e sociais sem interesses comerciais/lucrativos quanto projetos com foco para o empreendedorismo digital.

A plataforma conta atualmente com mais de setenta mil Aplicativos criados por usuários em cento e vinte países, organizados por categorias e disponíveis em uma galeria no próprio site ${ }^{6}$. No que tange à aprendizagem móvel, a Fábrica de Aplicativos se apresenta como uma possibilidade de criação de aplicativos educacionais para dispositivos móveis por não-desenvolvedores, uma possibilidade focada na colaboração de alunos e professores na produção de conteúdos educacionais digitais.

Para criar um aplicativo nessa plataforma tem-se alguns passos a serem seguidos, desde o mais simples até aqueles que exigirão atenção focada pelo usuário criador do aplicativo. Primeiramente é preciso realizar um cadastro na plataforma (solicita-se que os usuários tenham uma conta de e-mail para validação do cadastro a fim de evitar spammers) e criar uma senha de acesso (recomenda-se a leitura dos termos de uso). Depois dessa etapa concluídao usuário escolhe "Crie seu App" sendo rapidamente redirecionado para a área de desenvolvimento da plataforma.

$\mathrm{Na}$ área de desenvolvimento do dispositivo tem-se já os primeiros passos para a criação do aplicativo. Escolher a cor do tema ou do visual que será utilizado na customização do aplicativo (inserção de imagens personalizadas para abertura, cabeçalho e fundo) são apenas algumas das várias possibilidades oferecidas pela plataforma. Nessa área de desenvolvimento, uma imagem de um dispositivo (de modelo smartphone) não é apenas uma ilustração: nela os usuários podem ver como suas escolhas se apresentarão no dispositivo móvel - uma espécie de preview do seu dispositivo já criado. Uma das limitações dessa funcionalidade é o desenvolvimento de aplicativos para dispositivos móveis de telas maiores (como tablets de 7', 9' ou 10'): não é possível a visualização no momento de criação. Nas telas maiores a visualização só poderá ser realizada quando o aplicativo for finalizado e instalado no dispositivo.

Concluído o desenvolvimento é preciso definir os tipos de recursos que serão

5 Disponível em <http://www. fabricadeaplicativos.com.br> Acesso em 23 de abril de 2014.

6 Veja mais em <http://galeria.fabricadeaplicativos.com.br> Acesso em 22 de abril de 2014. 
utilizados para compor o aplicativo. Ao selecionar qualquer um dos recursos disponíveis, o usuário terá acesso a uma aba para inserir no sistema os conteúdos do aplicativo, de forma muito semelhante ao processo de envio de arquivos de áudio, vídeo, imagens, texto e links de outras plataformas. Ainda na opção gratuita é possível escolher os seguintes recursos para a integração das mídias digitais:

1. Álbum de Fotos: permite criar uma galeria de imagens no aplicativo. Para isso é necessário enviar uma imagem de cada vez e adicionar a ela uma legenda. Ainda é possível exportar álbuns e galerias de páginas web de hospedagem e compartilhamento de imagens como o Flickr?;

2. Galeria de Áudios: permite enviar arquivos de áudio em diversos formatos e criar de playlist ${ }^{8}$ dos arquivos;

3. Lista: permite adicionar imagens e textos ao aplicativo, sendo necessário o envio de alguma imagem e descrição sobre ela. Há também a opção lista de textos sem as imagens;

4. Mapa: permite inserir o link do Google Maps da localização que deseja exibir no aplicativo;

5. RSS e MRSS ${ }^{9}$ : permite inserir esses recursos agregadores de conteúdos disponíveis em blogs e outras páginas, para que os usuários do aplicativo possam acompanhar o conteúdo atualizado de blogs via dispositivo móvel;

6. Redes Sociais: permite que os usuários exportem os conteúdos disponíveis em suas contas de redes sociais como Twitter e Facebook ao aplicativo;

7. Vídeos: permite enviar vídeos de até $12 \mathrm{MiB}^{10}$ na plataforma. É possível também adicionar vídeos e canais do site YouTube ao aplicativo.

Após a escolha e seleção desses recursos para a criação dos conteúdos, o usuário é redirecionado para a etapa final para que ele nomeie, escolha e envie uma imagem que signifique, que represente seu aplicativo criado. Nesta etapa é possível escolher uma categoria para o aplicativo (para posterior publicação na galeria da plataforma) e adicionar uma descrição na forma de palavras-chave que facilitem a busca pela internet do aplicativo criado. Após selecionar a opção "publicar", o aplicativo, além ser disponibilizado na galeria da plataforma para a apreciação do público, poderá ser baixado em formado .apk (este formato permite a instalação do aplicativo em dispositivos móveis com sistema operacional Android e ainda a inserção deste em lojas como a Google Market).

Para os demais sistemas operacionais se faz necessária a criação de novas

7 O Flickr é uma plataforma da web de hospedagem e partilha de imagens fotográficas (e eventualmente de outros tipos de documentos gráficos, como desenhos e ilustrações) que permite novas maneiras de organizar as fotos e os vídeos.

8 Playlist é um termo em inglês que geralmente é utilizado no meio da radiodifusão para se referir a uma determinada lista de canções, que podem ser tocadas em sequência ou embaralhadas.

9 O MRSS (Media RSS) é uma extensão utilizada para agregar arquivos de áudio e vídeo aos já tradicionais feeds (RSS).

10 A sigla Mebibyte $(\mathrm{MiB})$ é uma unidade de medida de informação $\left(2^{20}\right.$ bytes $)$ e $12 \mathrm{MiB}$ significa vídeos curtos com resolução razoável. 
versões específicas. Para instalação do aplicativo diretamente da plataforma Fábrica de Aplicativos há duas opções: pelo link direto (app.vc/nome_do_aplicativo) ou via $Q R$ Code (código de barras bidimensional que pode ser lido e interpretado pela maioria dos aparelhos celulares que possuem câmera fotográfica). Esse código, após a decodificação, abre o link direto de download do aplicativo para a instalação no dispositivo móvel.

\section{Possibilidades e sugestões de aplicativos educacionais para dispositivos móveis construídos na plataforma web "Fábrica de Aplicativos"}

Destacamos nessa sessão algumas possibilidades e sugestões de aplicativos educacionais já desenvolvidos pelas autoras voltados para a educação básica. As possibilidades que selecionamos, abaixo listadas e resumidamente apresentadas, almejam oportunizar aos professores e alunos a criação de estratégias que não só atendam seus objetivos pedagógicos junto aos conteúdos programáticos dos currículos escolares integrando o uso das diferentes mídias digitais (imagens, textos, hipertextos, áudio, vídeo, blogs, mapas, redes sociais, etc.), mas também considerem estas tecnologias como fios suspensos de uma rede em constante busca pelos "nós" do conhecimento nesses tempos de Cultura Digital.

\subsection{Nutrilegal}

Para a construção do aplicativo Nutrilegal criou-se inicialmente um mapa mental com os tópicos da organização do menu, submenus e categorias. Em seguida buscou-se ícones, vídeos e imagens de alimentos e publicações sobre educação nutricional produzidas pelo Ministério da Saúde no Programa Nacional de Alimentação Escolar do Ministério da Educação e pela Turminha do Ministério Público (MP). Todas as publicações utilizadas são de domínio público.

O aplicativo Nutrilegal teve como objetivo apresentar informações sistematizadas sobre os principais nutrientes que compõe a nossa alimentação. Ele dispõe de uma videoteca saborosa, com vídeos e animações que destacam a importância de uma alimentação balanceada e rica em nutrientes para uma melhor qualidade vida. Observe que, na segunda figura abaixo, ao selecionar a categoria (aba) "as proteínas" o usuário tem acesso à informações detalhadas sobre cada nutriente alimentício disponível no aplicativo.

Os professores também podem usá-lo para a sistematização e organização dos objetivos escolares entre eles o de descobrir quais vitaminas estão presentes em determinados alimentos e quais deles são importantes para a manutenção de uma dieta saudável. Este aplicativo pode ser baixado na galeria da plataforma Fábrica de Aplicativos: (http://app.vc/nutri_legal) e instalado em qualquer dispositivo móvel com o sistema operacional Android (de qualquer versão). 

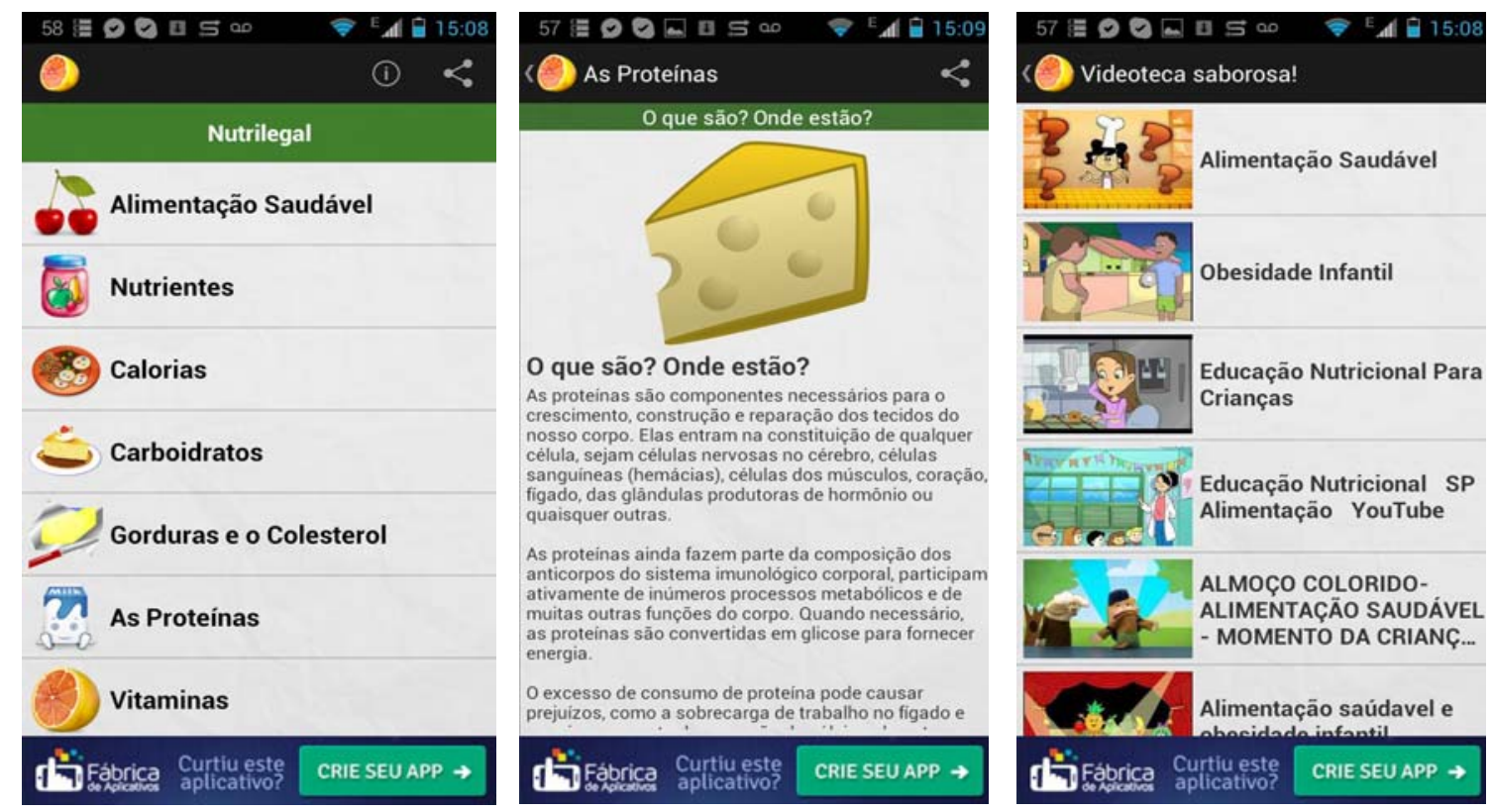

Figuras 3, 4 e 5: Captura das telas do aplicativo Nutrilegal em um smartphone.

\subsection{Literatura de Cordel}

O aplicativo Literatura de Cordel tem como objetivo reunir, disponibilizar e divulgar diversos materiais e informações sobre um gênero literário da cultura popular conhecido como Literatura de Cordel: poemas impressos vendidos a baixo custo ou divulgados em folhetos ilustrados com o processo de xilogravura (imagens com formas geométricas feitas em tábuas de madeira) ${ }^{11}$.

A Literatura de Cordel ganhou este nome porque em Portugal estes poemas eram expostos ao povo amarrados em cordões, estendidos em pequenas lojas de mercados populares ou até mesmo nas ruas. No Brasil, consequentemente pela colonização açoriana, estes "folhetos" hoje ainda são vendidos em feiras pelos próprios autores e podem ser encontrados também nas páginas da internet. A Literatura de Cordel faz grande sucesso especialmente na região do nordeste, pois que, além do preço baixo, o tom humorístico em muitos livretos retrata os fatos da vida cotidiana da cidade ou da região com a leveza de quem sabe marcar a oralidade da rima e do ritmo neste tipo de gênero literário popular.

O aplicativo Literatura de Cordel (http://app.vc/literatura_de_cordel) reúne informações históricas, biografia de cordelistas consagrados como o Patativa de Assaré e seus poemas, uma videoteca (com vídeos de uma série da TV Escola - Literatura de Cordel na Escola disponíveis para baixar na plataforma Domínio Público), notícias atualizadas de blogs e páginas da internet especializadas em Literatura de Cordel. $\mathrm{O}$ aplicativo ainda disponibiliza e compartilha links para o redirecionamento de páginas para o download gratuito de obras em formato digital de domínio público.

Este aplicativo apresenta possibilidades para que projetos envolvendo a divulgação de gêneros literários e musicais em geral, de artistas e manifestações culturais populares de cada região ou comunidade, possam ser estudados e 
compartilhados nos mais diversos objetivos escolares em sala de aula. Esse projeto pode envolver em sua construção alunos, professores e território educativo, contemplando através de imagens, vídeos, poemas, áudio e hiperlinks as mais variadas áreas do currículo escolar.
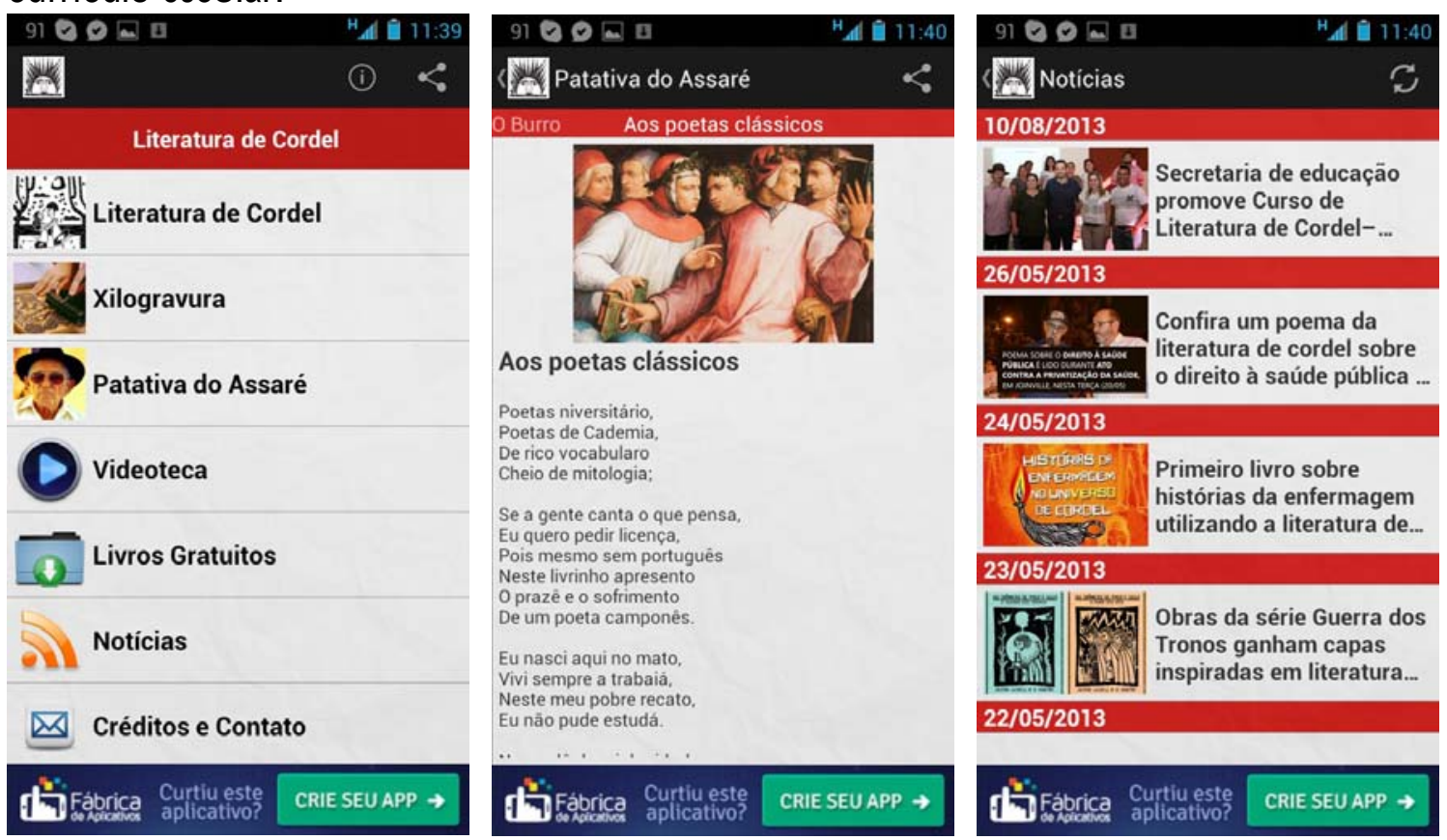

Figuras 6, 7 e 8: Telas do aplicativo Literatura de Cordel em um smartphone.

\subsection{Cantigas de Roda}

O aplicativo Cantigas de Roda é uma proposta de Educação Musical que pode ser usada também para crianças da Educação Infantil, considerando que este público já tem acesso a dispositivos móveis e muitas vezes seu próprio dispositivo pessoal ${ }^{12}$. Essa criação foi motivada a partir de uma análise dos aplicativos que têm sido produzido para este público, disponíveis em lojas como as do Google Market e do AppStore.

Numa rápida avaliação, podemos crer que atualmente os aplicativos em Iojas online apresentam mais consumos e publicidades economicamente focados do que aspectos pedagógicos propriamente ditos. Segundo o relatório "Mobile Apps for kids: Current Privacy Disclosures are Disappointing" (2012) da Federação de Comércio dos EUA (FTC), além do bombardeio publicitário, muitos dos aplicativos desenvolvidos para crianças capturam e repassam informações pessoais como geolocalização, endereços de IP e até mesmo contatos da agenda telefônica para outras empresas, sem nenhum aviso prévio para os usuários.

O aplicativo Cantigas de Roda (http://www.app.vc/cantigas_de_roda) que sugerimos reúne doze cantigas de roda onde as canções do folclore brasileiro podem ser ouvidas, cantadas, dançadas, brincadas e consultadas em suas informações históricas sobre suas origens, letras e videoteca. A partir da inserção de um canal do YouTube do compositor e educador musical Marcelo Serralva, são apresentadas cantigas de roda e

12 De acordo com a pesquisa "TIC Crianças 2010" do NIC.br, a partir de uma amostragem de 2.516 crianças de cinco a nove anos de idade, 59\% já tinham usado um telefone móvel”. 
atividades de ritmo, melodia, composição musical e contos musicais, sempre contando com a participação das crianças na interação com as propostas do educador.
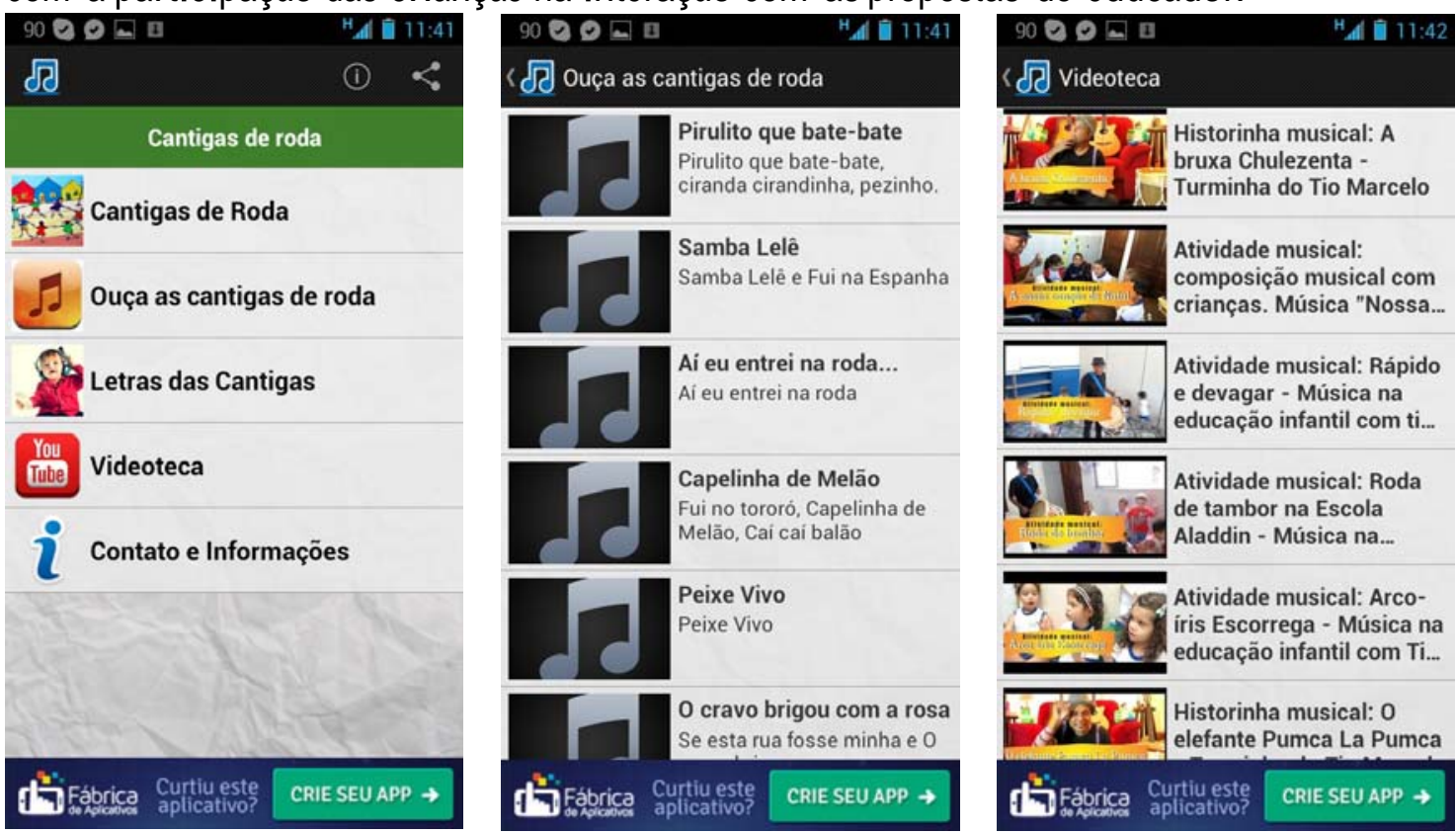

Figuras 9, 10 e 11: Telas do aplicativo "Cantigas de Roda" em um smartphone.

Com o acesso muitas vezes de forma irrestrita das crianças às mídias móveis, sem o devido cuidado na sua usabilidade por parte dos responsáveis, cada dia mais tem se mostrado emergente a criação e disponibilização de conteúdos e atividades que contribuam para o desenvolvimento das várias linguagens midiáticas possíveis, de forma transparente e a ética. A partir desta proposta totalmente livre e sem custo, podem ser criados aplicativos com canções de ninar onde os sons da natureza, dos animais e da cidade, dos instrumentos musicais e novas funcionalidades possam ser adicionadas ou excluídas de acordo com o desejo das crianças, dos professores e dos educadores.

\section{Considerações Finais}

Acreditamos que as possibilidades das tecnologias móveis e mais especialmente dos aplicativos na sala de aula possam contribuir para garantir a interconexão, a criação de comunidades e a inteligência coletiva no fluxo comunicativo da Cultura Digital e dos processos autorais e singulares deste tipo de construção colaborativa do conhecimento. Além da Fábrica de Aplicativos e as potencialidades presentes nas mídias móveis para a aprendizagem discutidas neste artigo, existem outras plataformas para a criação de aplicativos com características semelhantes que oferecem uma diversidade de recursos merecendo futuras investigações pedagógicas de suas potencialidades educativas.

Com o exponencial aumento dos aplicativos educacionais para os próximos anos será cada vez mais necessário o desenvolvimento de repositórios para o mapeamento, organização, categorização e disponibilização destes aplicativos nos próprios dispositivos móveis. Acreditamos que o aprendizado social dessas práticas pedagógicas poderá revolucionar não só as formas de acesso móvel ao conhecimento disponível na Cultura Digital, mas especialmente revolucionar os desejos de permanência dos alunos 
no espaço escolar. As trocas comunicativas na usabilidade destes aplicativos no ambiente escolar, que podem ser criados e recriados no formato de Recursos Educacionais Abertos (REA), podem alterar não só as condições de acesso ao conhecimento, mas especialmente seus modos de transmitir, estocar e produzir a própria informação.

\section{Referências}

BOLL, C.I. Protagonismo Educativo em Ações Interministeriais Contemporâneas: o programa Mais Educação e o programa Mais Cultura nas Escolas entrecruzando imaginações e conhecimentos autorais. Subtexto-Revista de Teatro do Galpão Cine Horto. Ano X Dez 13. no.10. Belo Horizonte: Fino Traço Editora, 2013.

CASTELLS, M. A Sociedade em Rede. 6a. Edição. São Paulo: Editora Paz e Terra. 2002.

KNOBEL, M.; LANKSHEAR Colin. A New Literacies Sampler. New York: Peter Lang. 2007.

LEMOS, A.; JOSGRILBERG, F. Comunicação e Mobilidade. Aspectos Socioculturais das Tecnologias Móveis no Brasil. Salvador: Edufba. 2009.

LEMOS, A. Cibercultura: tecnologia e vida social na cultura contemporânea. $5^{a}$ edição; Porto Alegre: Sulina, 2010.

LEVY, P. Cibercultura. São Paulo: Ed. 34, 1999.

MOURA, A. Geração Móvel: um ambiente de aprendizagem suportado por tecnologias móveis para a "Geração Polegar", 2010. Disponível em: http://adelinamouravitae.com.sapo.pt/gpolegar.pdf. Acesso em: 27 jan. 2014.

TAROUCO, L. M. R. et al. Objetos de Aprendizagem para M-Learning. In:

Anais do Congresso Nacional de Tecnologia da Informação e Comunicação. Florianópolis: $\quad$ SUCESU, $2004 . \quad$ Disponível em: $<$ http://www.cinted.ufrgs.br/CESTA/objetosdeaprendizagem_sucesu.pdf>. Acesso em: 28 jan. 2014.

TRAXLER, J. Defining, discussing and evaluating mobile learning: The moving finger writes and having writ. The International Review of Research in Open and Distance $\quad 2007 . \quad$ Learning. Disponível em: <http://www.irrodl.org/index.php/irrodl/article/view/346> Acesso em: 27 jan. 2014.

UNESCO. Policy Guidelines for Mobile Learning. 2013. Disponível em: http://unesdoc.unesco.org/images/0021/002196/219641E.pdf>. Acesso em: 28 jan. 2014.

VALENTE, J.A. (Org.). Formação de educadores para o uso da informática na escola. Campinas, SP: Unicamp/Nied, 2003.

VALENTIM, Hugo. Para uma Compreensão do Mobile Learning. Reflexão sobre a utilidade das tecnologias móveis na aprendizagem informal e para a construção de ambientes pessoais de aprendizagem. Gestão de Sistemas de e-Learning, 
Universidade Nova de Lisboa, Lisboa. 2009. Dissertação de Mestrado. 